\title{
Protective Effect of Botulinum C/D Mosaic Toxoid against Avian Botulism
}

\author{
Masato TAKEDA $^{1)}$, Hiroko KASAI ${ }^{1)}$, Yasushi TORII ${ }^{1)}$, Masafumi MUKAMOTO ${ }^{1)}$, Tomoko KOHDA ${ }^{1)}$, \\ Kentaro TSUKAMOTO ${ }^{1)}$ and Shunji KOZAKI ${ }^{1) *}$ \\ ${ }^{1)}$ Department of Veterinary Science, Graduate School of Life and Environmental Sciences, Osaka Prefecture University, 1-1 Gakuen-cho, \\ Sakai, Osaka 599-8531, Japan
}

(Received 6 October 2005/Accepted 1 December 2005)

ABSTRACT. Avian botulism is a paralytic disease caused by a toxin produced by Clostridium botulinum type C. Since type C isolates from cases of avian botulism produced a neurotoxin consisting of a mosaic form of parts of type $\mathrm{C}$ and $\mathrm{D}$ neurotoxins, we examined the antitoxin titers in the convalescent sera of botulism-affected birds which belonged to family Anatidae. ELISA using the C/D mosaic neurotoxin as an antigen revealed that the antibody was detected in the sera at 2 weeks, but not at 5 weeks after the onset, suggesting that the antibody only appeared for a short period in the convalescent phase. However, we failed to detect the antibody titers with antichicken IgG instead of anti-duck IgG. We therefore examine the immunological properties of IgG among different families and species. The results revealed that different species of IgG in the same family exhibited strong cross-reactivity. Ducks immunized once with the toxoid together with a commercial oil-adjuvanted vaccine were found to develop sufficient antibody to protect against a challenge with a lethal toxin dose. The ELISA titers did not correspond to the neutralization titers in the sera of immunized ducks at the early stage during immunization. These findings suggest that the neutralizing titer was more useful than the ELISA titer for evaluating the protection against the toxin, but the ELISA technique may be applicable for detecting the occurrence of botulism.

KEY WORDS: avian botulism, C/D mosaic toxin, Clostridium botulinum, vaccination.

Clostridium botulinum toxins have been classified into seven immunologically distinct types, types A through $\mathrm{G}$. Botulism is characterized by a generalized muscular weakness that extends gradually to all skeletal muscles and results in death from respiratory dysfunction. Human botulism mainly involves types A, B, E, and F, and whereas the majority of cases of animal botulism are caused by type $C$, cattle and sheep are also particularly susceptible to botulism caused by type D [17,21]. Botulism in humans and domestic animals is usually caused by the ingestion of preformed toxin in food or feed. Avian botulism seems to be divided into two types. In the first one, type $\mathrm{C}$ toxin produced in birds or other carcasses is ingested by fly larvae and then a healthy bird eats the toxic maggots, resulting in the development of botulism symptoms because the bird absorbs the toxin released from the maggots through the digestive tract $[2,26]$. The other type is categorized as a toxico-infection. In an outbreak of botulism in broiler chickens, no source of preformed toxin was found, but a number of type $\mathrm{C}$ organisms were detected in feed, litter, and other specimens [16]. Toxin production may take place in the intestines of chickens.

C. botulinum type $\mathrm{C}$ strains produce two different-sized progenitor toxins with molecular masses of $500 \mathrm{kDa}(\mathrm{L}$ toxin) and $300 \mathrm{kDa}$ (M toxin) [17]. Each toxin consists of neurotoxin and nontoxic component(s). M toxin is a complex of neurotoxin and a nontoxic component possessing no hemagglutinin activity, and $\mathrm{L}$ toxin is a complex of $\mathrm{M}$ toxin

\footnotetext{
* Correspondence to: Kozaki, S., Department of Veterinary Science, Graduate School of Life and Environmental Sciences, Osaka Prefecture University, 1-1 Gakuen-cho, Sakai, Osaka 599-8531, Japan.
}

and hemagglutinin [8]. The neurotoxin is composed of a light chain (L-chain, $50 \mathrm{kDa}$ ) and a heavy chain (H-chain, $100 \mathrm{kDa})$. The L-chain has been characterized as a zinc protease [19]. The H-chain is composed of two domains. The carboxyl-terminal domain $\left(\mathrm{H}_{\mathrm{C}}\right)$ is involved in binding to the receptor on the neural membrane, and the amino-terminal domain $\left(\mathrm{H}_{\mathrm{N}}\right)$ is responsible for internalization (or translocation) of the L-chain into nerve cells [4, 18].

From 1993 to 2000, avian botulism occurred often in a zoo in Osaka Prefecture in Japan, and more than 300 birds (which belonged to 2 families and 41 species) were eventually killed. We examined etiologically the events and isolated the causative organisms. We then attempted to analyze immunologically and genetically the characteristics of the toxins produced by the isolates and obtained some evidence that they produced a mosaic form of neurotoxin consisting of two-thirds type $\mathrm{C}$ neurotoxin (the entire Lchain and the HN domain) and one-third type $\mathrm{D}$ neurotoxin (the $\mathrm{H}_{\mathrm{C}}$ domain). Isolates from some other cases of avian botulism also possessed such a $\mathrm{C} / \mathrm{D}$ mosaic neurotoxin gene, whereas the isolates from mink and equine botulism possessed a typical type $\mathrm{C}$ neurotoxin gene [22]. Although it is widely accepted that formalin-inactivated toxoid is effective for vaccination for humans, mink and cattle, there is no available vaccine for the prevention of avian botulism. Generally, to achieve immunization, toxoid should be injected more than twice in order to develop sufficient antibody for protection, but it seems to be impractical to capture birds often enough to meet the immunization schedule. To avoid this problem, it is desirable to establish an immunization procedure that can achieve the development of sufficient antibody by injecting birds only once. The procedure 
may be useful for preventing botulism in rare species of birds displayed in zoos.

In the present study, we attempted to immunize ducks with the toxoid together with a commercial oil-adjuvanted vaccine containing inactivated Salmonella Enteritidis and evaluated the resultant antibody titers by ELISA and a neutralization test. We also provide available data on the crossreactivity of immunoglobulin $\mathrm{G}$ (IgG) among different species of birds, which is important for the development of an immunological detection method in birds.

\section{MATERIALS AND METHODS}

Bacterial strains and toxins: C. botulinum strains 003-9 (C/D mosaic), CB19 (type C), and CB16 (type D) were used in this study. The toxin of strain 003-9 was purified according to the method of Kurazano et al. [10]. During purification, two different-sized ( $\mathrm{L}$ and $\mathrm{M}$ ) toxins were obtained in the final step of gel filtration on Sephadex G-200, but M toxin was mainly used in this study because $M$ toxin possesses a specific toxicity at least twice higher than that of $\mathrm{L}$ toxin. The neurotoxin was isolated from $\mathrm{M}$ toxin by anion exchange chromatography as previously described [9]. The neurotoxins of strains CB19 and CB16 were obtained by the same procedure as described above. $\mathrm{M}$ toxin was detoxified at $30^{\circ} \mathrm{C}$ by dialyzing against $0.4 \%$ formalin in $0.01 \mathrm{M}$ phosphate buffer, pH $8.0(0.2 \mathrm{mg} / \mathrm{ml})$ [13]. The reaction was allowed to proceed for 10 days. The inactivation of the toxin was confirmed by intraperitoneal injection into mice (ddy, 5 weeks old; Japan SLC Inc., Shizuoka, Japan) at a $0.5-\mathrm{m} l$ dose.

Isolation of IgG from egg yolk: The yolks were collected from the abandoned eggs of various avian species. Egg yolk liquid was diluted twofold with $0.075 \mathrm{M}$ phosphate buffer, $\mathrm{pH} 7.4$, containing $0.075 \mathrm{M} \mathrm{NaCl}$ (PBS). The mixture was treated at room temperature for $30 \mathrm{~min}$ with an equal volume of chloroform to remove fat from the egg yolk according to the procedure described by Ntakarutimana et al. [14]. After the aqueous phase was collected, solid ammonium sulfate was added to $33 \%$ saturation. After centrifugation at $8,000 \times \mathrm{g}$ to remove the precipitate, solid ammonium sulfate was further added to the supernatant to achieve a final concentration of $40 \%$. The precipitate was then collected by centrifugation at $8,000 \times \mathrm{g}$ for $10 \mathrm{~min}$ and dissolved with $17.5 \mathrm{mM}$ phosphate buffer, $\mathrm{pH} 7.5$, containing $0.5 \mathrm{M} \mathrm{NaCl}$. The concentrate was purified on a Superdex $200 \mathrm{pg}$ column (Amersham Biosciences K.K., Tokyo, Japan) equilibrated with the same buffer. The IgG was eluted with the same buffer and concentrated with a YM-10 membrane.

Preparation of anti-avian $\operatorname{IgG}$ : Antisera against avian IgGs were obtained from rabbits (Kiwa Laboratory Animals Co., Ltd., Wakayama, Japan) weighing about $3 \mathrm{~kg}$. A 0.5 $\mathrm{m} l$ sample containing $100 \mu \mathrm{g}$ of purified IgG from egg yolk was emulsified in an equal volume of Freund's complete adjuvant (Becton, Dickinson and Company, Franklin Lakes, NJ, U.S.A.) and injected subcutaneously into a rabbit. After 4 weeks, the same amount of IgG with Freund's incomplete adjuvant (Becton, Dickinson and Company) was injected subcutaneously. The same procedures were repeated twice. The animal was bled 2 weeks after the last injection. The IgG fraction of rabbit anti-avian IgG was isolated by the method of Steinbuch and Audran [20]. The anti-avian IgG was labeled with biotin. In brief, the anti-avian IgG (2 mg/ $\mathrm{m} l$ ) was dialyzed against $0.05 \mathrm{M}$ sodium bicarbonate buffer, $\mathrm{pH} 8.5$, and then reacted with $0.26 \mathrm{mM}$ EZ-link ${ }^{\mathrm{TM}}$ sulfoNHS-Biotin (Pierce Biotechnology, Inc., Rockford, IL, U.S.A.) for $2 \mathrm{hr}$ at $4^{\circ} \mathrm{C}$. After the reaction, the mixture was dialyzed against PBS to remove excess biotin. The biotinlabeled $\operatorname{IgG}$ was diluted to $1.0 \mathrm{mg} / \mathrm{m} l$ and stored at $4{ }^{\circ} \mathrm{C}$ until use.

Immunization of ducks with toxoid: Domestic ducks (Anas platyrhynchos var. domestica) (1.5 to $1.8 \mathrm{~kg}$ weight, 5 months old; Kiwa Laboratory Animals) were immunized with $\mathrm{M}$ toxoid. In order to evaluate the development of antibody with a single-shot vaccination, $\mathrm{M}$ toxoid $(200 \mu \mathrm{g} / \mathrm{m} l)$ was mixed with two volumes of a commercial oil-adjuvanted vaccine containing inactivated Salmonella Enteritidis (Inacti/vac-SE, Ghen Corporation, Gifu, Japan). As a high-dose group, four ducks were immunized subcutaneously with the oil vaccine mixture containing $50 \mu \mathrm{g}$ of toxoid. As a low-dose group, four other ducks were also immunized with the oil vaccine mixture containing $10 \mu \mathrm{g}$ of toxoid. Partial bleeding was performed at a week intervals. Five weeks after the primary injection of toxoid, the immunized ducks were challenged intravenously with $M$ toxin diluted with $0.01 \mathrm{M}$ phosphate buffer, $\mathrm{pH} 6.2$, containing $0.2 \%$ gelatin (gelatin-PB).

ELISA: ELISA was performed in 96-well microtiter plates (Becton, Dickinson and Company). To determine the antitoxin titers of sera from botulism-affected birds or immunized ducks, the neurotoxin $(0.2 \mu \mathrm{g} / 0.1 \mathrm{~m} l)$ of strain 003-9 was coated onto microtiter plates. After coating, the plates were washed and blocked overnight with $0.2 \mathrm{ml}$ of $0.2 \%$ bovine serum albumin (BSA; Sigma-Aldrich Corp., St. Louis, MO, U.S.A.) in PBS at $4^{\circ} \mathrm{C}$. Duck serum samples were diluted twofold serially and $0.1 \mathrm{~m} l$ of each dilution was added to a well. After incubation for $2 \mathrm{hr}$ at $37^{\circ} \mathrm{C}, 0.1 \mathrm{ml}$ of biotin-labeled rabbit anti-duck $\operatorname{IgG}(4 \mu \mathrm{g} / \mathrm{m} l)$ was added. After incubation for $2 \mathrm{hr}$ at $37^{\circ} \mathrm{C}, 0.1 \mathrm{ml}$ of avidin-labeled horseradish peroxidase (Cappel Laboratories, West Chester, PA, U.S.A.) was added. After incubation for $30 \mathrm{~min}$ at $37^{\circ} \mathrm{C}$, substrate $\left(0.08 \% 5\right.$-aminosalicylic acid- $0.05 \% \mathrm{H}_{2} \mathrm{O}_{2}$, 9:1) was added and the mixtures were allowed to react for $45 \mathrm{~min}$ at $37^{\circ} \mathrm{C}$. The absorbance at $450 \mathrm{~nm}$ was measured with a microplate reader. The ELISA titer was expressed as the highest dilution factor showing an absorbance higher than double that of negative control serum.

In order to examine the immunological cross-reactivities of IgG among avian species, $10 \mu \mathrm{g}$ of rabbit anti-avian IgG

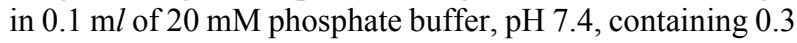
$\mathrm{M} \mathrm{NaCl}$. After incubation for $2 \mathrm{hr}$ at $37^{\circ} \mathrm{C}$, the plates were washed five times with the above buffer containing $0.05 \%$ Tween 20. The wells were then blocked by the addition of $0.2 \mathrm{ml}$ of $1 \%$ skim milk (Becton, Dickinson and Company) 
in PBS. After overnight incubation at $4^{\circ} \mathrm{C}$, the plates were washed five times with PBS containing $0.05 \%$ Tween 20. Avian serum samples were diluted twofold serially and 0.1 $\mathrm{m} l$ of each dilution was added to a well. After incubation for $2 \mathrm{hr}$ at $37^{\circ} \mathrm{C}, 0.1 \mathrm{ml}$ of biotin-labeled rabbit anti-avian IgG $(4 \mu \mathrm{g} / \mathrm{m} l)$ was added. After incubation for $2 \mathrm{hr}$ at $37^{\circ} \mathrm{C}, 0.1$ $\mathrm{m} l$ per well of avidin-horseradish peroxidase conjugate was added. The rest of the procedure to determine the crossreactivity was performed as described above.

Neutralization potency of duck antisera: The neutralization potency of immunized duck antisera was determined by a mouse bioassay according to the method previously described [23]. In brief, the standard type $C$ antitoxin (Chiba Serum Institute, Chiba, Japan) was diluted in gelatinPB so as to contain $0.025,0.032,0.05,0.063$, or 0.08 international units (IU) per $0.25 \mathrm{ml}$. The test toxin (M toxin of strain 003-9) used as the standard antitoxin was diluted so as to contain one test dose (the dose of the toxin, when mixed with 0.05 IU of antitoxin, killing half of the mice weighing about $16 \mathrm{~g}$ in $72 \mathrm{hr}$ when injected intraperitoneally) per $0.25 \mathrm{ml}$. Equal quantities of each dilution of standard antitoxin or a test serum sample and the test toxin dilution were mixed well. The mixtures were allowed to stand for $1 \mathrm{hr}$ and $0.5-\mathrm{m} l$ doses were injected intraperitoneally into two mice weighing about $16 \mathrm{~g}$. The injected mice were observed for 3 days. The potency was expressed relative to that of the standard antitoxin.

Determination of toxicity: Toxicity in mice was assessed by intraperitoneal injection (ip) of $0.5-\mathrm{m} l$ volumes of serially twofold dilutions into groups of 4 mice per dilution. In order to assess the lethality of $\mathrm{M}$ toxin in ducks, the toxin was diluted serially four-fold with gelatin-PB, and each dilution was injected intravenously at a $0.5-\mathrm{m} l$ dose into the wing-veins of four 5-month-old ducks. The mice and ducks were observed for 4 days and the $50 \%$ ip or intravenous (iv) lethal dose per $\mathrm{m} l$ was calculated according to the method of Reed and Muench [15].

Other methods: The protein content was estimated using the method of Lowry et al. [12]. SDS-PAGE was performed by the method of Laemmli under reducing conditions [11]. For immunoblotting, the neurotoxin separated by SDSPAGE was transferred electrophoretically to a PVDF membrane (Immobilon-P, Millipore Corp. Billerica, MA, U.S.A.) [24]. The membrane was then incubated for $30 \mathrm{~min}$ at room temperature with duck antitoxin sera diluted in PBS containing $0.5 \%$ skim milk. It was washed with PBS and then treated for $1 \mathrm{hr}$ with biotin-labeled anti-duck IgG (10 $\mu \mathrm{g} / \mathrm{m} l)$. After washing, the membrane was treated for 30 min with avidin-labeled horseradish peroxidase. After washing, it was exposed to the substrate solution $(0.05 \%$ diaminobenzidine and $0.003 \% \mathrm{H}_{2} \mathrm{O}_{2}$ in $\left.\mathrm{PBS}\right)$. The reaction was stopped by a rinse with distilled water.

\section{RESULTS}

Determination of antibody titers of botulism-affected birds with various anti-avian IgGs: We obtained the serum

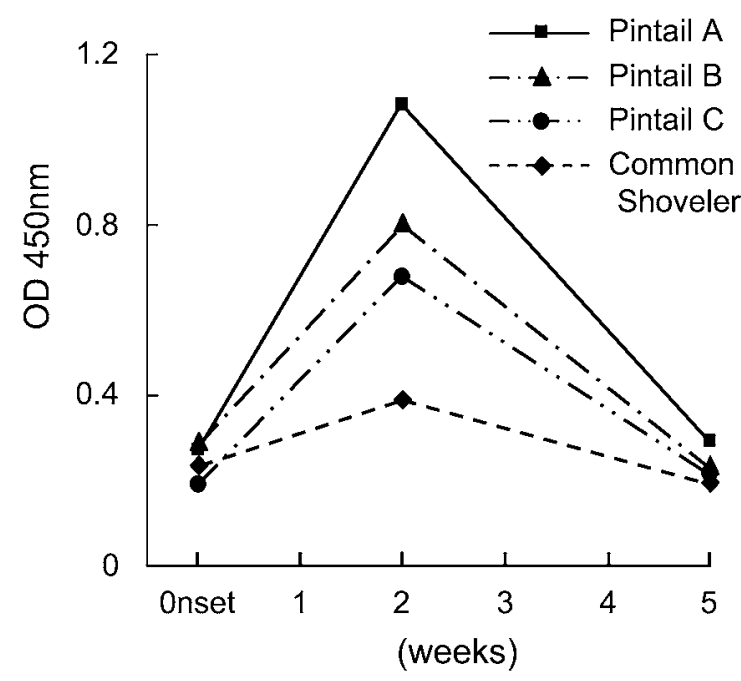

Fig. 1. Antibody levels in the convalescent sera obtained from botulism-affected birds. Each serum sample was diluted to $2^{8}$ fold with PBS-Tween 20 and subjected to ELISA with rabbit anti-duck IgG.

samples of four birds suffering from avian botulism [three pintail (Anas acuta) and one common shoveler (Anas clypeata)], all of which belonged to the family Anatidae. The serum samples were taken at the onset of the disease, and 2 and 5 weeks after the onset, i.e., during the convalescent stage. When serially diluted sera were added to wells coated with the neurotoxin and titrated with biotin-labeled antiduck IgG, the sera obtained 2 weeks after the onset were found to contain antibody against the neurotoxin. However, the antibody titers were found to decrease rapidly in all of the sera obtained 5 weeks after the onset (Fig. 1). When biotin-labeled anti-chicken IgG was used for the determination of the antibody titer of the sera, no positive reaction was observed, suggesting that the individual IgGs in family Anatidae possesses different antigenicity from chicken IgG (data not shown).

In order to further examine the immunological crossreactivity among avian IgGs, we prepared rabbit anti-IgGs against IgGs obtained from the egg yolks of little egret (Egretta garzetta) and hermit ibis (Geronticus eremita) as well as duck and chicken (Gullus gullus domerticum). After labeling each of the rabbit anti-avian IgG preparations with biotin, we conducted ELISA with 14 avian species of sera. As shown in Table 1, the anti-duck IgG reacted with sera obtained from the birds which belonged to the same family, but not with sera from birds belonging to other families. The other anti-IgGs also appeared to interact with the sera of the birds in the homologous family, although the IgGs seemed to cross-react partially between little egret and grey heron (family Ardeidae) and hermit ibis (family Threskionithidae). Anti-chicken IgG reacted with duck IgG to a very low extent.

Determination of antibody in ducks given a single vacci- 
Table 1. Immunological cross-reactivity among avian IgGs

\begin{tabular}{|c|c|c|c|c|c|c|}
\hline \multirow[b]{2}{*}{ Order } & \multirow[b]{2}{*}{ Family } & \multirow[b]{2}{*}{ Species } & \multicolumn{4}{|c|}{ ELISA titer $\left(\log _{2}\right)$ with rabbit anti-avian IgGs } \\
\hline & & & Domestic Duck & Chicken & Little Egret & Hermit Ibis \\
\hline \multirow[t]{8}{*}{ Anseriformes } & \multirow[t]{8}{*}{ Anatidae } & Domestic Duck & $19^{\text {a) }}$ & $<5$ & $<5$ & $<5$ \\
\hline & & Swan Goose & 16 & $<5$ & $<5$ & $<5$ \\
\hline & & Ruddy Shelduck & 16 & $<5$ & $<5$ & $<5$ \\
\hline & & Mandarin Duck & 17 & $<5$ & $<5$ & $<5$ \\
\hline & & Mallard & 18 & $<5$ & $<5$ & $<5$ \\
\hline & & Pintail & 18 & $<5$ & $<5$ & $<5$ \\
\hline & & Tufted Duck & 17 & $<5$ & $<5$ & $<5$ \\
\hline & & Goosander & 17 & $<5$ & $<5$ & $<5$ \\
\hline Galliformes & Phasianidae & Chicken & 11 & 17 & $<5$ & $<5$ \\
\hline \multirow[t]{5}{*}{ Ciconiiformes } & \multirow[t]{3}{*}{ Ardeidae } & Little Egret & $<5$ & $<5$ & 18 & 14 \\
\hline & & Black-Crowned Night Heron & $<5$ & $<5$ & 16 & 13 \\
\hline & & Grey Heron & $<5$ & $<5$ & 17 & 12 \\
\hline & \multirow[t]{2}{*}{ Threskiornithidae } & Hermit Ibis & $<5$ & $<5$ & 14 & 16 \\
\hline & & Scarlet Ibis & $<5$ & $<5$ & 13 & 16 \\
\hline
\end{tabular}

a) The values are expressed as the reciprocal of the highest dilution giving a positive reaction with the respective rabbit anti-avian IgG.

Table 2. ELISA titers of sera of ducks immunized with C/D mosaic toxoid ${ }^{\text {a) }}$

\begin{tabular}{ccccccc}
\hline \multirow{2}{*}{$\begin{array}{c}\text { Toxoidamt. } \\
(\mu \mathrm{g})\end{array}$} & Duck & \multicolumn{5}{c}{ ELISA titer $\left(\log _{2}\right)$} \\
\cline { 3 - 7 } & & $1 \mathrm{wk}$ & 2 wks & 3 wks & 4 wks & 5 wks \\
\hline \multirow{2}{*}{10} & $\mathrm{a}$ & $<5^{\text {b) }}$ & 17 & 16 & 15 & 15 \\
& $\mathrm{~b}$ & 5 & 18 & 16 & 15 & 14 \\
& $\mathrm{c}$ & $<5$ & 15 & 15 & 14 & 14 \\
50 & $\mathrm{~d}$ & $<5$ & 19 & 17 & 16 & 15 \\
& $\mathrm{e}$ & 13 & 16 & 17 & 18 & 17 \\
& $\mathrm{f}$ & 8 & 20 & 18 & 16 & 15 \\
& $\mathrm{~g}$ & 12 & 20 & 19 & 18 & 17 \\
& $\mathrm{~h}$ & $<5$ & 18 & 17 & 16 & 15 \\
\hline
\end{tabular}

a) The sera of ducks without immunization showed no positive reaction in ELISA.

b) The values are expressed as the reciprocal of the highest dilution giving a positive reaction.

nation shot: The ducks immunized once with toxoid in an inactivated oil-adjuvanted vaccine were monitored for antibody production by ELISA and the neutralization test. In ELISA, all ducks receiving the toxoid at either a 10 or $50 \mu \mathrm{g}$ dose gave ELISA titers of 15 to 20 at 2 weeks after immunization. These titers persisted at roughly the same level until 5 weeks (Table 2). By contrast, the neutralization titers of ducks immunized with a 50- $\mu$ g dose were higher than those with a $10-\mu \mathrm{g}$ dose, although their ELISA titers were equal. In the ducks given a $50-\mu \mathrm{g}$ toxoid dose, the neutralization titers tended to gradually increase until 5 weeks after immunization (Table 3). In immunoblotting, the sera from ducks immunized with toxoid reacted with the L- and H-chains of the neurotoxins of strains 003-9 (C/D mosaic) and CB19 (type C), but only with the H-chain of strain CB16 (type D). The intensities of the two bands derived from the C/D mosaic neurotoxin appeared to be higher than those from the other neurotoxins, suggesting the possibility that the $C / D$ mosaic neurotoxin possesses intrinsic antigenicity which differs from those of type $\mathrm{C}$ and $\mathrm{D}$ neurotoxins (Fig. 2).

Challenge of toxin to immunized ducks: When the $\mathrm{LD}_{50}$ of $\mathrm{M}$ toxin in ducks was determined by iv injection, the lethal- ity, equivalent to one iv $\mathrm{LD}_{50}$, was $4.0 \times 10^{3}$ mouse ip $\mathrm{LD}_{50}$. We then attempted to challenge immunized and non-immunized ducks with 4 iv $\mathrm{LD}_{50}$. All immunized ducks survived, but the non-immunized ones died within $30 \mathrm{hr}$ after toxin injection (Table 4). We examined the remaining toxicity in the blood of non-immunized ducks. More than $60 \%$ of the toxin administrated was still detected even just before killing.

\section{DISCUSSION}

Several varieties of birds, including ducks, waterfowl, and broiler chickens, are affected by type $\mathrm{C}$ botulism-causing organisms $[3,6]$. In previous reports, gallinaceous birds were shown to be highly susceptible to the culture supernatant of type C strains, but were resistant to that of type D strains [7]. Recently, we examined the neurotoxin gene of isolates associated with avian botulism from different sources and found that they all possessed both types $C$ and $\mathrm{D}$ genes or a mosaic gene consisting of parts of types $\mathrm{C}$ and D neurotoxin genes [22]. These observations suggest that it would be more promising to use a $\mathrm{C} / \mathrm{D}$ mosaic toxin rather 
Table 3. Neutralization titers of sera of ducks immunized with C/D mosaic toxoid ${ }^{\text {a) }}$

\begin{tabular}{ccccccc}
\hline $\begin{array}{c}\text { Toxoid amt. } \\
(\mu \mathrm{g})\end{array}$ & Duck & \multicolumn{5}{c}{ Neutralization titer $(\mathrm{IU} / \mathrm{m} l)$} \\
\cline { 3 - 7 } 10 & $\mathrm{1}$ wk & 2 wks & $3 \mathrm{wks}$ & $4 \mathrm{wks}$ & $5 \mathrm{wks}$ \\
\hline & $\mathrm{a}$ & $<0.25$ & 5.0 & 1.6 & 1.6 & 5.0 \\
& $\mathrm{~b}$ & $<0.25$ & 2.5 & 1.6 & 2.5 & 3.2 \\
& $\mathrm{c}$ & $<0.25$ & 0.8 & 1.6 & 2.5 & 3.2 \\
50 & $\mathrm{~d}$ & $<0.25$ & 12.7 & 12.7 & 12.7 & 16.0 \\
& $\mathrm{e}$ & $<0.25$ & 2.0 & 12.7 & 50.7 & 80.6 \\
& $\mathrm{f}$ & $<0.25$ & 5.0 & 5.1 & 16.0 & 50.7 \\
& $\mathrm{~g}$ & $<0.25$ & 10.1 & 8.0 & 8.0 & 25.4 \\
& $\mathrm{~h}$ & $<0.25$ & 2.5 & 6.4 & 20.1 & 25.4 \\
\hline
\end{tabular}

a) The sera of ducks without immunization did not contain neutralizing antibody.

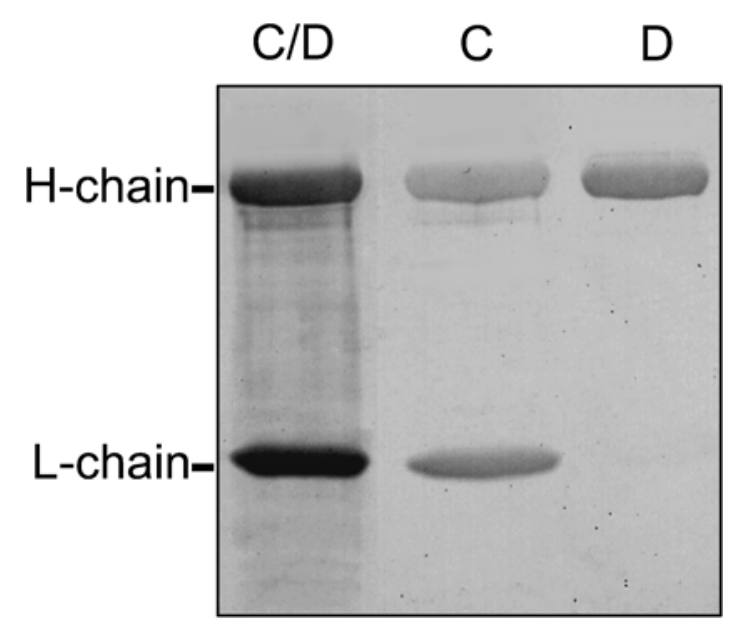

Fig. 2. Reactivity of the antiserum of a duck immunized with $\mathrm{C} / \mathrm{D}$ mosaic toxoid in immunoblotting analysis. Serum (from duck "e" shown in Tables 2 and 3 ) obtained 5 weeks after the primary injection was used in this experiment. The neurotoxins (each $2 \mu \mathrm{g}$ ) were electrophoresed on a $10 \%$ SDS-polyacrylamide gel in the presence of DTT, electroblotted, and immunostained with the serum diluted 100 -fold. The immunoreactive bands were visualized with diaminobenzidine. C/D;003-9 neurotoxin, C; CB19 neurotoxin, D; CB16 neurotoxin.

than a typical type $\mathrm{C}$ toxin as the antigen for diagnosis and vaccination against avian botulism.

In this study, we surveyed the convalescent sera of botulism-affected birds which belonged to the family Anatidae by the use of rabbit anti-duck IgG in ELISA and detected antibody against the neurotoxin of strain 003-9 in the sera at 2 weeks, but not at 5 weeks, after the onset. These findings indicate that the antibody is only observed during a short period of time in the convalescent stage, suggesting that sufficient antibody to protect against reinfection was not developed in the affected birds.

Although it has been found that the IgG of an individual species of bird possesses its own immunological specificity [1], no systematic investigation concerning the interspecies cross-reactivity of IgGs has been performed. When we
Table 4. Challenge of ducks immunized with $\mathrm{C} / \mathrm{D}$ mosaic toxoid

\begin{tabular}{ccc}
\hline $\begin{array}{c}\text { Toxoid amt. } \\
(\mu \mathrm{g})\end{array}$ & $\begin{array}{c}\text { No. of ducks } \\
\text { challenged }\end{array}$ & $\begin{array}{c}\text { No. of ducks } \\
\text { that survived }\end{array}$ \\
\hline 50 & 4 & 4 \\
10 & 4 & 4 \\
0 & 2 & 0 \\
\hline
\end{tabular}

All ducks were injected with 003-9 M toxin intravenously.

attempted to determine the antibody level in the same family as ducks by using rabbit anti-chicken $\mathrm{IgG}$, we failed to detect a positive reaction. We therefore examined the immunological cross-reactivity of IgG among different families and species. The results indicated that IgGs from different species in the same family exhibited a strong crossreaction, suggesting that the immunological specificity of $\mathrm{IgG}$ is dependent upon the respective family group. The data also provide a good explanation of why the antibody of botulism-affected birds in the convalescent phase could be detected by the use of anti-IgG of different birds belonging to the same family.

Inactivated oil-emulsion vaccine has been used for immunization in chickens to obtain an adjuvant effect [5]. In this study, we found that ducks immunized once with the toxoid together with the commercial oil-adjuvated vaccine succeeded in the development of the antitoxin antibody, and the antibody level was sufficient to protect against a challenge with a lethal dose. The ELISA titers did not correspond to the neutralization titers in the sera of immunized duck, especially at the early stage. Similar observations have been reported concerning the sera of human volunteers vaccinated with botulinum toxoid [23]. The ELISA titer was correlated with the neutralizing titer in serum samples with high potency. From these findings, it was concluded that the neutralizing titer was more useful than the ELISA titer for evaluating the protection against the toxin, but the ELISA technique appears to be applicable for detecting the occurrence of botulism.

Recently, we tried to characterize the receptors for type $\mathrm{C}$ and $\mathrm{D}$ neurotoxins and found that the binding of the type $\mathrm{C}$ 
toxin to the receptor is ganglioside-dependent, while type D binding is not dependent on ganglioside [25]. Since the C/D mosaic toxin has binding characteristics similar to those of type D toxin regarding the recognition of the receptor, it is probable that the mechanisms of their toxic actions differ from each other. It is, therefore, useful to employ $\mathrm{C} / \mathrm{D}$ mosaic toxin as an antigen for the prevention of avian botulism. We are now examining the usefulness of this toxin in a practical setting.

ACKNOWLEDGEMENTS. This work was supported in part by grants-in-aid for Scientific Research from the Japan Society for the Promotion of Science. We would like to thank the Yokohama Zoological Gardens, "Zoorasia" for collecting eggs and sera of various avian species.

\section{REFERENCES}

1. Baghian, A., Reyes, C.V., Mendoza, A., Tully, T.N., Jr. and Kousoulas, K.G. 1999. Production of a rabbit anti-cockatiel immunoglobulin $\mathrm{G}$ and characterization of its cross-reactivities with immunoglobulin G of other psittacine species. Avian Dis. 43: 48-54.

2. Bengtson, I.A. 1922. Preliminary note on a toxin-producing anaerobe isolated from the larvae of Lucilia caesar. Pub. Health Rep. 37: 164-170.

3. Dohms, J.E. and Cloud, S.S. 1982. Susceptibility of broiler chickens to Clostridium botulinum type C toxin. Avian Dis. 26: 89-96.

4. Finkelstein, A. 1990. Channels formed in phospholipid bilayer membranes by diphtheria, tetanus, botulinum and anthrax toxin. J. Physiol. 84: 188-190.

5. Fukanoki, S., Matsumoto, K., Mori, H. and Takeda, R. 2000. Relation between antigen release and immune response of oil adjuvanted vaccines in chickens. J. Vet. Med. Sci. 62: 571-574.

6. Giltner, L.T. and Couch, J.F. 1932. Western duck sickness and botulism. Science 12: 660.

7. Gross, W.B. and Smith, L.D. 1971. Experimental botulism in gallinaceous birds. Avian Dis. 15: 716-722.

8. Inoue, K., Fuginaga, Y., Honke, K., Yokota, K., Ikeda, T., Ohyama, T., Takeshi, K., Watanabe, T., Inoue, K. and Oguma, K. 1999. Characterization of haemagglutinin activity of Clostridium botulinum type C and D 16 S toxins, and one subcomponent of haemagglutinin (HA1). Microbiology 145 : 2533-2542.

9. Kozaki, S., Sakaguchi, S. and Sakaguchi, G. 1974. Purification and some properties of progenitor toxins of Clostridium botulinum type B. Infect. Immun. 10: 750-756.

10. Kurazono, H., Shimozawa, K., Sakaguchi, G., Takahashi, M., Shimizu, T. and Kondo, H. 1985. Botulism among penned pheasants and protection by vaccination with $\mathrm{C} 1$ toxoid. Res.
Vet. Sci. 38: 104-108.

11. Laemmli, U. K. 1970. Cleavage of structural proteins during the assembly of the head of bacteriophage T4. Nature (Lond.) 227: 680-685.

12. Lowry, O. H., Rosebrough, N. J., Farr, A. L. and Randall, R. J. 1951. Protein measurement with the Folin phenol reagent. $J$. Biol. Chem. 193: 265-275.

13. Miyazaki, S., Iwasaki, M. and Sakaguchi, G. 1977. Clostridium botulinum type D progenitor toxin: Purification, molecular structure, and some immunological properties. Infect. Immun. 17: 395-401.

14. Ntakarutimana, V., Demedts, P., van Sande, M. and Scharpe, S. 1992. A simple and economical strategy for downstream processing of specific antibodies to human transferrin from egg yolk. J. Immunol. Methods 153: 133-140.

15. Reed, L.J. and Muench, H. 1938. A simple method of estimating fifty per cent endpoints. Am. J. Hyg. 27: 493-497.

16. Roberts, T.A. and Collings, D.F. 1973. An outbreak of type-C botulism in broiler chicken. Avian Dis. 17: 650-658.

17. Sakaguchi, G. 1982. Clostridium botulinum toxins. Pharmacol. Ther. 19: 165-194.

18. Simpson, L.L. 2004. Identification of the major steps in botulinum toxin action. Annu. Rev. Pharmacol. Toxicol. 44: 167193.

19. Simpson, L.L., Maksymowych, A.B. and Hao, S. 2001. The role of zinc binding in the biological activity of botulinum toxin. J. Biol. Chem. 276: 27034-27041.

20. Steinbuch, M. and Audran, R. 1969. The isolation of $\operatorname{IgG}$ from mammalian sera with the aid of caprylic acid. Arch. Biochem. Biophys. 134: 279-284.

21. Sugiyama, H. 1980. Clostridium botulinum neurotoxin. Microbiol. Rev. 44: 419-448.

22. Takeda, M., Tsukamoto, K., Kohda, T., Matsui, M., Mukamoto, M. and Kozaki, S. 2005. Characterization of the neurotoxin produced by isolates associated with avian botulism. Avian Dis. 49: 376-381.

23. Torii, Y., Tokumaru, Y., Kawaguchi, S., Izumi, N., Maruyama, S., Mukamoto, M., Kozaki, S. and Takahashi, M. 2002. Production and immunogenic efficacy of botulinum tetravalent (A, B, E, F) toxoid. Vaccine 20: 2556-2561.

24. Towbin, H., Staehelin, T. and Gordon, J. 1979. Electrophoretic transfer of proteins from polyacrylamide gels to nitrocellulose sheets: procedure and some applications. Proc. Natl. Acad. Sci. U.S.A. 76: $4350-4354$.

25. Tsukamoto, K., Kohda, T., Mukamoto, M., Takeuchi, K., Ihara, H., Saito, M. and Kozaki, S. 2005. Binding of Clostridium botulinum type $\mathrm{C}$ and $\mathrm{D}$ neurotoxins to ganglioside and phospholipid: novel insights into the receptor for clostridial neurotoxins. J. Biol. Chem. 280: 35164-35171.

26. Wobeser, G. 1997. Avian botulism-another perspective. J. Wildl. Dis. 33: 181-186. 